\title{
Effects of selected catalysts on the catalytic wet oxidation of pharmaceutical sludge
}

\author{
LIU Jun, ZENG Xu* and ZHAO Jianfu \\ State Key Laboratory of Pollution Control and Resources Reuse \\ College of Environmental Science and Engineering, Tongji University, Shanghai, China \\ *zengxu@tongji.edu.cn
}

Keywords: Wet oxidation; Pharmaceutical sludge; COD removal; Volume reduction.

Abstract. Catalyst selection for the catalytic wet oxidation of pharmaceutical sludge was investigated. The selected catalysts include homogeneous catalysts, alkaline catalyst, Zeolite and supported Zeolite catalysts, and metallic oxide catalysts. Experiments were performed at $220^{\circ} \mathrm{C}$ for 60 min with $\mathrm{O}_{2}$ initial pressure 1.0 MPa. Results showed that Zeolite and supported Zeolite catalyst significantly enhanced the wet oxidation of pharmaceutical sludge. Especially the supported Zeolite catalyst with $\mathrm{CeO}_{2}-\mathrm{CuO}$. These results were important for the volume reduction and stabilization and harmlessness of pharmaceutical sludge using catalytic wet oxidation method.

\section{Introduction}

Large amounts of pharmaceutical sludge were generated because of the quick development of pharmaceutical industry in the past decades. It should be point out that the pharmaceutical sludge always include some heavy metal ion and non-degradable organic pollutant in the environment, therefore, the harmlessness, stabilization and volume reduction treatment of pharmaceutical sludge are very important. Nowadays, the drying and burning treatment are the mainly methods. However, the cost is always very high, and the subsequent pollutants could be produce from the burning treatment. Therefore, green and low cost method is strongly desired.

Recently, advanced oxidation processes (AOPs) are considered as one of the most effective treatment technologies for the decomposition of bioresistant organic contaminants ${ }^{[1]}$. Wet oxidation has shown high effectiveness and promising property including benzene, biphenyls, amines and pyridine ${ }^{[2-4]}$. This process performed under high temperature $\left(150 \sim 350{ }^{\circ} \mathrm{C}\right)$ and pressure $(2.0 \sim 15.0$ $\mathrm{MPa})$ conditions. This process is a green and environmental-friendly technology because there is almost no harmful materials or secondary pollution to the environment ${ }^{[5,6]}$. Catalytic wet air oxidation (CWAO) decreases the operating conditions, enhances the reaction rate, and shortens the residence time $^{[7]}$. Much research has been conducted on the development of catalysts for use in CWAO over the past decades ${ }^{[8,9]}$. Compared to the biological, electrochemical or photocatalytic treatments, CWAO is more efficient at treating high concentrations of organic pollutants, CWAO has gained wide attention from many scholars in recent years, and it has been used to treat various industrial wastewaters containing recalcitrant organics, such as dyes ${ }^{[10]}$.

In this study, effects of selected catalysts on the catalytic wet oxidation of pharmaceutical sludge were investigated in this study. The selected catalysts include homogeneous catalysts, alkaline catalyst, Zeolite and supported Zeolite catalysts, and metallic oxide catalysts. The supported Zeolite catalyst were prepared with maceration method. Experiments were performed at $220{ }^{\circ} \mathrm{C}$ for 60 min with $\mathrm{O}_{2}$ initial pressure 1.0 MPa with different kind of catalyst.

\section{Materials and methods}

Materials. The catalysts used in this study were purchased from Sinopharm Chemical Reagent (Shanghai, China), as received without further purification. The supported Zeolite catalyst were prepared with maceration method. The raw pharmaceutical wastewater was obtained from a synthetic pharmaceutical factory, which was located in the east of China. The characters of the raw sludge solution is: COD $15000 \sim 19000 \mathrm{mg} / \mathrm{L}, \mathrm{pH}$ 8.0 9.0. 
Experimental procedure. All experiments in this study were performed in a SUS316 reactor, as shown in Fig. 1. The reactor was purchased from Anhui Kemi Machinery Technology Co. Ltd, China, which has an internal volume of $100 \mathrm{~mL}$. The experimental procedure is: $50 \mathrm{~mL}$ of pharmaceutical sludge solution and catalyst were put into the reactor, and the initial oxygen pressure was $1.0 \mathrm{MPa}$. Then the reactor was heated, the temperature was increased to $220{ }^{\circ} \mathrm{C}$, which was decided on our previous study. The reactor was removed from the oven and allowed to cool to room temperature, 60 min after the desired reaction temperature was achieved. The pressure in the reactor corresponded to the self-pressurization with saturated vapor pressure.

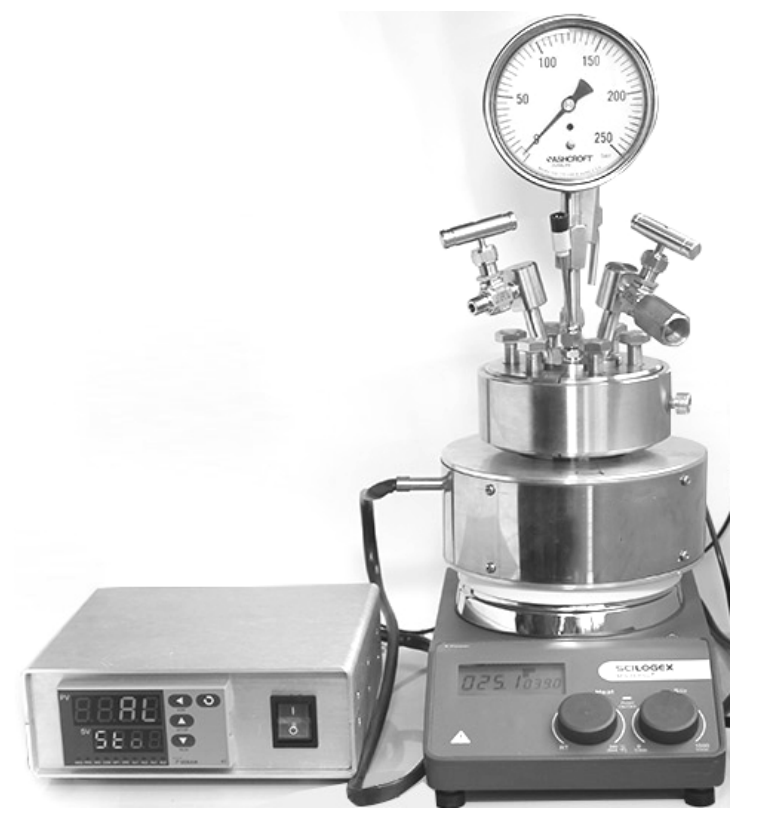

Fig. 1 Picture of experimental reactor.

Analysis method. COD was measured by the potassium dichromate oxidation method. $\mathrm{pH}$ was measured by $\mathrm{pH}-201$, Hanna Corporation, Italy).

\section{Results and discussion}

Effect of homogeneous catalysts. It was reported that homogeneous catalysts can enhance the wet oxidation efficiency significantly. Therefore, in this section. some homogeneous catalysts were collected to study the effects of homogeneous catalysts, including $\mathrm{FeSO}_{4}, \mathrm{MnSO}_{4}, \mathrm{Ce}\left(\mathrm{NO}_{3}\right)_{3}$, $\mathrm{Cu}\left(\mathrm{NO}_{3}\right)_{2}$. Also, the reaction without catalyst was done to compare the results. The experiments were performed at $220{ }^{\circ} \mathrm{C}$ for $60 \mathrm{~min}$ with initial oxygen pressure $1.0 \mathrm{MPa}$ and catalyst $0.1 \mathrm{~g}$. As shown in Fig. 2, the COD degradation was accelerated significantly when the homogeneous catalyst was added. The effect of $\mathrm{Cu}\left(\mathrm{NO}_{3}\right)_{2}$ was the highest. The total COD removal rate could be up to $60 \%$. After the reaction, carboxylic acids with small molecule amount, such as formic acid or acetic acid, were produced. It has been reported that these small molecule carboxylic acids are not easy to be oxidized under hydrothermal conditions, therefore the COD removal rate cannot be up to $90 \%$ or $100 \%$. Also, we have analyzed VSS removal rate. However, the results showed that there were almost no difference. In addition, it should be noted that the obtained data indicate that some by-products were formed in the reaction, some of them are probably non-oxidizable and remain in the final solution under the employed conditions. To compare the effects of different catalysts with same reaction condition, the experiments in the following runs were done at $220^{\circ} \mathrm{C}$ for 60 min with initial oxygen pressure $1.0 \mathrm{MPa}$. 


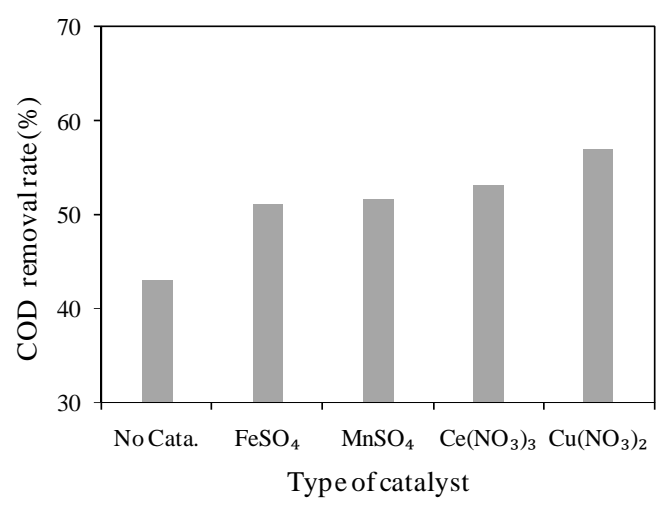

Fig. 2. Effect of homogeneous catalysts $\left(220^{\circ} \mathrm{C}, 60 \mathrm{~min}, \mathrm{O}_{2}\right.$ initial pressure $1.0 \mathrm{MPa}$, catalyst $\left.0.1 \mathrm{~g}\right)$.

Effect of alkaline catalysts. The alkali can be used as a kind of catalyst in the wet oxidation. Therefore, in this study, several kinds of alkali were chose to study the effect of alkaline catalyst. The alkali includes $\mathrm{Na}_{2} \mathrm{CO}_{3}, \mathrm{NaHCO}_{3}, \mathrm{NaOH}, \mathrm{KOH}$. The results can be seen in Fig. 3. The effect of alkaline catalyst showed different results comparing with homogeneous catalysts. With alkaline catalyst, the COD removal rate decreased and the VSS removal rate increased significantly. These results were very interesting. These results indicated that the alkaline catalyst can influence the solid sludge degradation significantly. This behavior was also expected because the increase of VSS removal rate increased the COD of solution. Therefore, the COD removal rate decreased. The results of VSS removal rate were very good, which showed near $90 \%$ of VSS were removed, which means that the volume reduction affection were significantly. To be noted, for the pharmaceutical sludge, which is a kind of hazardous waste, the volume reduction is very important.

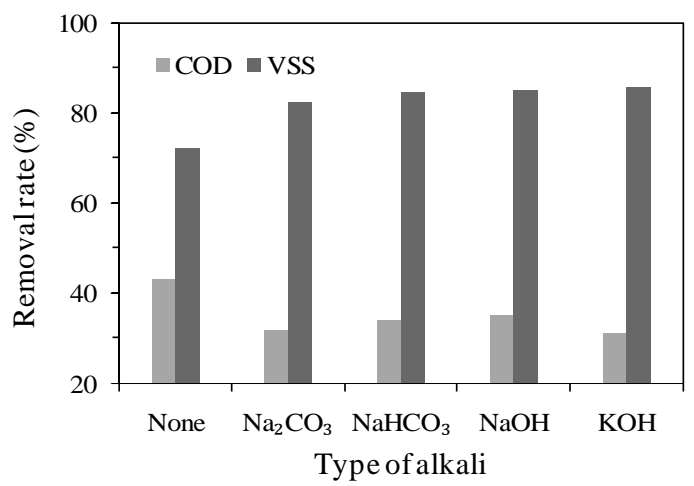

Fig. 3. Effect of alkaline catalyst $\left(220^{\circ} \mathrm{C}, 60 \mathrm{~min}, \mathrm{O}_{2}\right.$ initial pressure $1.0 \mathrm{MPa}$, catalyst $\left.0.5 \mathrm{~g}\right)$.

Effect of Zeolite and supported Zeolite as catalysts. Zeolite and supported Zeolite catalysts were always used in chemical oxidize reaction. Therefore, the effects of Zeolite and supported Zeolite catalysts were studied in this study. The supported Zeolite catalyst were prepared with maceration method. Fig. 4 shows the effects of Zeolite and supported Zeolite catalysts with COD and VSS removal rate. Cata. (1), (2) and (3) were supported with $\mathrm{CeO}_{2}, \mathrm{CuO}$ and $\mathrm{CeO}_{2}-\mathrm{CuO}$ separately. The results showed that the COD removal rate was enhanced significantly with Zeolite and supported Zeolite catalysts. At the same time, the VSS removal rates were also increased obviously. Comparing the results of homogeneous catalysts and alkaline catalysts, the Zeolite and supported Zeolite catalysts showed good results with high increase of COD and VSS removal rate. 


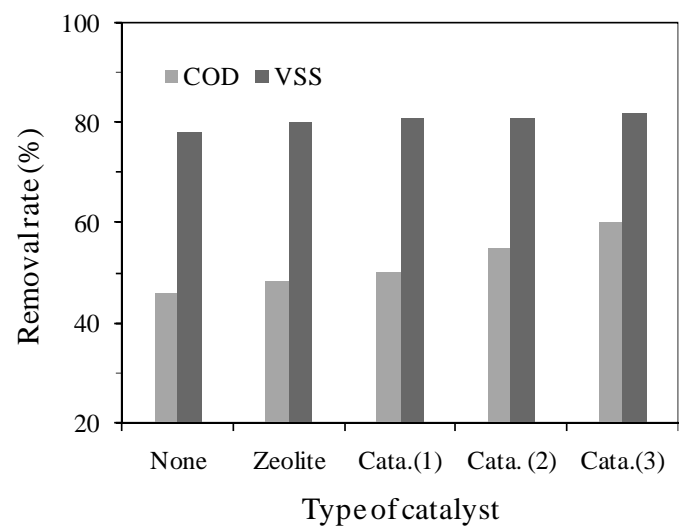

Fig. 4. Effect of Zeolite and supported Zeolite $\left(220^{\circ} \mathrm{C}, 60 \mathrm{~min}, \mathrm{O}_{2}\right.$ initial pressure $1.0 \mathrm{MPa}$, catalyst $\left.0.5 \mathrm{~g}\right)$.

Effect of metallic oxide catalysts. To investigate the effect of metallic oxide catalysts, experiments were performed with $\mathrm{MnO}_{2}, \mathrm{Fe}_{3} \mathrm{O}_{4}, \mathrm{CuO}$. Results can be seen in Fig. 5. As shown in Fig. 5, the COD removal rate was similar. However, $\mathrm{CuO}$ can influence the VSS removal rate significantly. Comparing with the the Zeolite and supported Zeolite catalysts, the result was still not ideal. It showed be note that, the metallic oxide catalysts used in this study were common and cheap. Some other metallic oxide catalysts still shown be studied for the catalytic affection of sludge wet oxidation in the future.

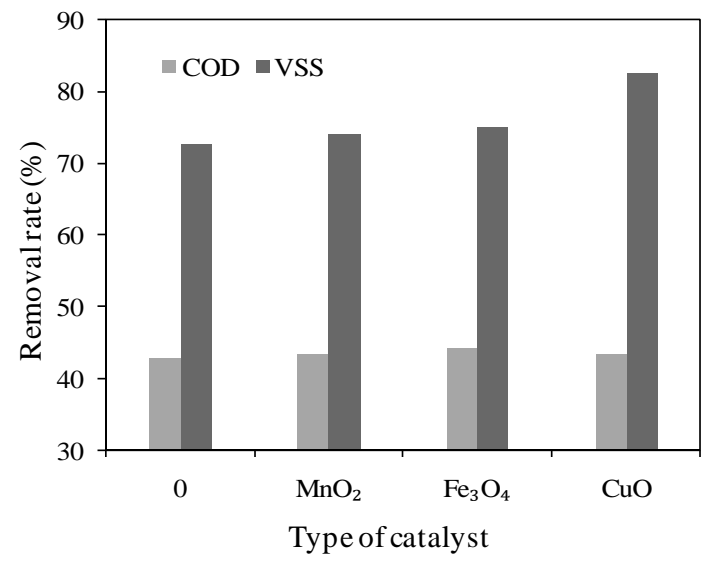

Fig. 5. Effect of metallic oxide catalysts $\left(220^{\circ} \mathrm{C}, 60 \mathrm{~min}, \mathrm{O}_{2}\right.$ initial pressure $1.0 \mathrm{MPa}$, catalyst $\left.0.5 \mathrm{~g}\right)$.

\section{Conclusions}

In this study, effects of selected catalysts on the catalytic wet oxidation of pharmaceutical sludge were investigated. The selected catalysts include homogeneous catalysts, alkaline catalyst, Zeolite and supported Zeolite catalyst, and metallic oxide catalysts. Experiments were performed at $220^{\circ} \mathrm{C}$ for 60 min with $\mathrm{O}_{2}$ initial pressure 1.0 MPa. Results showed that the effects of Zeolite and supported Zeolite catalyst were the best. Especially the supported Zeolite catalyst with $\mathrm{CeO}_{2}-\mathrm{CuO}$. In the next step of our research, we will focused on the supported Zeolite catalyst, which showed significant enhancement for the catalytic wet oxidation of pharmaceutical sludge.

\section{References}

[1] H. Yu, E. Nie, J. Xu. Water Res., 2013, 47: 1909-1918.

[2] P. E. Savage, S. Gopalan, T. I. Mizan, C. J. Martino, E. E. Brock. AIChE J., 1995, 41: 1723-1778.

[3] R. Weber, Sh. Yoshida, K. Miva. Environ. Sci. Tech., 2002, 36: 1839-1844.

[4] B. Veriansyah, J. D. Kim, J. C. Lee. J. Hazardous Materials, 2007, 147: 8-14.

[5] B. Veriansyah, T.-J. Park, J.S. Lim, Y.-W. Lee. J. Supercritical Fluids, 2005, 34: 51-61. 
[6] Z. Fang, S. K. Xu, R. L. Smith Jr., K. Arai, J.A. Kozinski. J. Supercritical Fluids, 2005, 33 : 247-258.

[7] H. T. Gomesa, J. L. Figueiredo, J. L. Faria, et al.. Journal of Molecular Catalysis A: Chemical 2002, 182(1): 47-60.

[8] M. Bemardi, D. Cretenot, S. Deleris. Catalysis Today 2010, 157: 420-424.

[9] E. Slavik, R. Galessi, A. Rapisardi. Drying Technology 2015, 33(11): 1309-1317.

[10] B. Meunier. Science 2002, 296: 270-271. 